\title{
Genetic diversity among sorghum landraces and polymorphism assessment of local improved varieties for stay-green trait
}

\author{
Nofou OUEDRAOGO ${ }^{13^{*}}$, Jacob SANOU ${ }^{1}$, Hamidou TRAORE ${ }^{1}$, Vernon GRACEN ${ }^{2}$, \\ Pangirayi TONGOONA ${ }^{3}$ and Eric Y DANQUAH ${ }^{3}$
}

\footnotetext{
${ }^{1}$ Institute of Environment and Agricultural Research (INERA), BP 910 Bobo Dioulasso, Burkina Faso ${ }^{2}$ Department of Plant Breeding and Genetics, 520 Bradfield Hall, Cornell University, Ithaca, NY 14850, USA ${ }^{3}$ West Africa Centre for Crop Improvement (WACCI), University of Ghana, BMP 30, Legon, Accra, Ghana

*Corresponding author; E-mail: nouedraogo@wacci.edu.gh /nofou2008@yahoo.fr; Tel: +22670033072
}

\begin{abstract}
Microsatellites or simple sequence repeats (SSR) are playing an important role in molecular breeding. This investigation was undertaken to study the genetic diversity among local sorghum accessions from two different agro-ecological zones of Burkina Faso and to assess the polymorphism within local improved varieties and a source (B35) exhibiting the stay-green trait. One hundred and eighty-six local and some exotic accessions were assessed using 26 SSR markers (including 14 markers linked to stay-green QTLs). DNA was extracted using Mixed Alkyl Trimethyl Ammonium Bromide method from dried sample after collection of leaves from three week old plantlets. The average number of alleles per locus was 4 with a medium value of gene diversity $(H e=0.45)$ across loci, indicating a low level of dissimilarity among local accessions. The genetic differentiation was significant between local and exotic materials and accessions were grouped according to their racial affiliation. The important finding was the presence of private alleles at markers linked to stay-green loci in the background of some local guinea accessions. The polymorphism between B35 and some local improved varieties for stay-green QTL indicates that most of the linked markers could be used in a breeding program through marker-assisted selection.
\end{abstract}

(C) 2017 International Formulae Group. All rights reserved.

Keywords: Sorghum, diversity, stay-green trait, marker, polymorphism.

\section{INTRODUCTION}

Sorghum (Sorghum bicolor [L] Moench) has been cultivated since ancient times and is currently a staple cereal in arid and semi-arid regions of the world. Among the world's cereals, it ranks fifth in annual tonnage [Food and Agriculture Organization of United Nations (FAO), 2015]. It constitutes the major cereal and food crop for rural population in Burkina Faso where traditional varieties (landraces or local accessions) are dominant in the traditional cropping system, with a preponderance of the Guinea botanical race (Barro-Kondombo et al., 2008). Traditional varieties are important genetic resources, their conservation would maintain genetic diversity and their valorization would ensure food security (Missihoun et al., 2012).

According to Harlan (1975), West Africa is a centre of diversification of 
sorghum and Burkina Faso seems to be the heart of that centre (Zongo, 1991). Sorghum remains the major cereal grown in poorest areas of world. However, production is still limited by biotic and abiotic constraints. Among these constraints, drought is the main factor that contributes to crop yield losses around the world (Araus et al., 2002). In semiarid areas, rural populations are faced by a reduction and erratic distribution of rainfall during cropping seasons (Zougmoré, 2003). In Burkina Faso, post-flowering drought is the most frequent drought and considerably affects sorghum yield. This reduces the food security status for rural farmers. According to Assogbado et al. (2009), diversification of agriculture via the use of diverse genetic resources could develop new and durable production systems.

The biological basis of world food security relies on variability of genetic resources (FAO, 2009). During evolution, cultivated plants acquired some traits enabling them to survive and become adapted to new environmental conditions. Sorghum genotypes that are tolerant to post-flowering drought have been identified (Payton et al., 2003). These genotypes remain photosynthetically active after physiological maturity of the grain (Kebede et al., 2001). They are referred to as stay-green genotypes. They maintain green leaves longer, resist precocious plant death and have normal grain filling during postflowering drought. Stay-green genotypes have a reduced rate of translocation of stored assimilates from the stem and extend the period of active assimilation (Borrell et al., 2000). The stay-green trait has been characterized in a limited number of genotypes including BTx642, ET36-1, M35, SC56 and K19. The most common source of the stay-green trait has been BTx642, formerly named B35. Several markers linked to the stay-green QTLs have been identified in B35 (Harris et al., 2007; Kassahun et al.,
2009). Overall, six stay-green QTLs for postflowering drought tolerance have been identified and four (labeled as Stg1, Stg2, Stg3 and Stg4) are considered as major stay green QdTLs while two (StgA and StgB) are considered as minor QTLs. These have been consistently identified in a range of environments (Subudhi et al., 2000; Harris et al., 2007) and in different genetic backgrounds (Subudhi et al., 2000).

Many studies have been conducted to assess sorghum diversity in Burkina Faso but they were focused on agro-morphological characterization (Sawadogo et al., 2014; Nebie et al., 2013; Barro-Kodombo et al., 2008) and enzymatic characterization (Zongo, 2005). Molecular characterizations have been limited to specific collections (Barrakodombo, 2010) or to particular types of sorghum [sweet grain sorghum (Sawadogo, 2015) and sweet stem sorghum (Nebie, 2014)]. The present study aims to assess diversity among 186 traditional sorghum varieties from three regions located in two agro-ecological zones in Burkina Faso and determine the polymorphism for "stay-green" QTLs within some local improved varieties and a stay-green source to develop breeding strategies for improvement.

\section{MATERIALS AND METHODS \\ Plants materials}

One hundred and eighty-six (186) accessions were used for this study. One hundred and seventy-six including local improved varieties were collected in 1999 from three districts located in two agroecological zones of the country. Ninety were collected in the west, 46 in the southwest and 40 in the eastern part of the country. The accessions were self-pollinated regularly for seeds regeneration and conservation. Ten exotic varieties were included in the study. TX7000 (bicolor), TX7078 (bicolor), ET36-1 (guinea-caudatum), and B35, a source of stay- 
green QTLs were obtained from International Crops Research Institute for the Semi-Arid Tropics (ICRISAT). Tiandougou (guinea), Tiandougou-coura and Grinkan (intermediate caudatum-guinea) were obtained from Mali. Three drought tolerant varieties (Samurai 1, Samurai 2 and Pahat) from Indonesia were also included.

\section{Molecular characterization}

\section{Samples collection and DNA extraction}

Leaf samples were collected from three week old seedlings and dried in an oven at 40 ${ }^{\circ} \mathrm{C}$ for three days. After drying, leaf samples were ground using a Geno-grinder (RETSCH) at 500 strokes per minute for 9 minutes and then DNA was extracted following a Mixed Alkyl Trimethyl Ammonium Bromide (MATAB) method (Frost et al., 2007). Finally, extracted DNA samples were dissolved in $150 \mu \mathrm{l}$ of TE (TE1X) and kept at ambient temperature overnight and then stored at $-20{ }^{\circ} \mathrm{C}$. The working concentration of about $5 \mathrm{ng}$ per $\mu \mathrm{l}$ was obtained from dilution of initial DNA solution after checking DNA concentrations and quality on $0.8 \%$ agarose gels.

\section{SSR Markers, Polymerase chain reaction (PCR) and polyacrylamide gel electrophoresis}

Eighteen markers (mSBCIR238, mSBCIR222, $\quad m S B C I R 225, \quad m S B C I R 314$, mSBCIR188, mSBCIR243, gpsb014, gpsb079, gpsb098, gpsb123, gpsb133, gpsb136, gpsb158, Sbagb02, gpsb032, Xcup011, Xtxp015 and Sb5-236) used were part of sorghum SSR kit (http://sorghum.cirad.fr/SSR_kit) which provide good coverage of the sorghum nuclear genome (Billot et al., 2012). The remaining markers (Xcup043, Xtxp023, Xtxp003, Xtxp055，Xtxp072， Xtxp123， Xtxp225,
Xtxp285) were developed by Bhattramakki et al. (2000), Kong et al. (2000) and Schloss et al. (2002). The genotyping was performed at “Centre d'Etude Régional pour l'Amélioration de l'Adaptation à la Sécheresse", (CERAAS) genotyping Platform of Thies (Senegal). The forward primer was designed with a 5'-end M13 extension (5'CACGACGTTGTAAAACGAC-3'). The PCR were realized in 35 cycles using a thermocycler (MWG AG Biotech). It was done in $10 \mu \mathrm{l}$ reaction volumes containing $25 \mathrm{ng}$ of genomic DNA template, $0.1 \mathrm{mM}$ of dNTPs, $1 \mathrm{x}$ buffer, $200 \mu \mathrm{M}$ of $\mathrm{MgCl} 2,0.1 \mu \mathrm{M}$ of both forward and reverse primers, $0.1 \mu \mathrm{M}$ of IRdye, $0.1 \mathrm{U}$ of ampliTaq polymerase enzyme and double distilled water. IRDyeH700 or IRDyeH800-labeled PCR products were subjected to electrophoresis in 6.5\% polyacrylamide gels with a Licor 4300 DNA Analyser system. Electrophoresis was carried out using $20 \mathrm{ml}$ of polyacrylamide $6.5 \%$ polyacrylamide, $200 \mathrm{ml} 10 \mathrm{X} \mathrm{TBE}$ diluted to $1 \mathrm{~L}, 175 \mu \mathrm{l}$ ammonium per-sulphate (APS), and $25 \mu$ TEMED). The gel was run at $1500 \mathrm{~V}$ and $35 \mathrm{~mA}$ constant power supplies, for 2 hours using a licor DNA analyser unit. Two control panel DNA samples were used in each electrophoresis. For polymorphism assessment, the bands on the gel were coded as "a", "b", “c", “d", "e", "f" and "g" based on their allele number. The missing data were scored as " $\mathrm{x}$ ".

\section{Data analysis}

The software PowerMarker version 3.25 was used to determine the descriptive parameters for genetic diversity such as the average number of allele per locus $(\mathrm{N})$, the polymorphism rate $(\mathrm{P})$, the observed heterozygosity $(\mathrm{Ho})$ and gene diversity or expected heterozygosity $(\mathrm{He})$ across loci and populations and the Polymorphism Information Content (PIC). 
The software GenAlex version 6.41 (Rockall and Smouse PE, 2006) was used to determine the number of different alleles $(\mathrm{Na})$, loci with private (rare) alleles and number of common alleles. It was also used to perform the structure of genetic diversity through two fixation indexes (F-statistic) based on heterozygosity rate. The $\boldsymbol{F}_{i s}$ measures the heterozygosity deficit in a sub-population and indicates the intra-population genetic differentiation. $\boldsymbol{F}_{\text {st }}$ measures the genetic differentiation among sub-populations. Nei genetic distance was also determined among the population. An Analysis of Molecular Variance (AMOVA) was performed to explain the genetic variation. Darwin software, version 5.0.158 (Perrier and Jacquemoud-Collet, 2006) was used to display graphical genetic relationship. The factorial analysis was performed using RogersTanimoto dissimilarity index and the cluster was obtained using the "Neighbor-Joining" method.

\section{RESULTS}

\section{Genetic polymorphism and allelic diversity patterns}

Twenty-six SSRs markers were used in the present study. A total of 108 alleles were identified in the study. The number of alleles ranged from 2 to 7 with an average of 4 alleles per locus (Table 1). The number of different alleles (Na) per locus ranged from 2.42 (exotic accessions) to $3.23,3.24$ and 3.50 , respectively, from Eastern, southwestern and Western regions accessions. The number of common alleles was low in the exotic material $(0.19)$ and relatively high within accessions of local populations (Eastern and Western Regions $=0.23$ and Southwest Region $=0.26$ ) (Figure 1). The PIC ranged from 0.05 at the locus gpsb133 to 0.76 at the locus Xtxp285 with an average of 0.40 per locus (Table 1). Among the 26 SSR markers analyzed, 4 markers produced 22 private or rare alleles observed in local accessions of Eastern and Western regions. Among the 4 markers, 3 (Xtxp15, Xtxp123 and Xtxp285) detected specific alleles for stay-green QTLs in the traditional varieties or local accessions. The specific allele at the locus Xtxp23 was detected in six traditional varieties (PSE206, PSE226A, PSE234, PSE288, PSE65 and PSE69). The locus Xtxp015 was detected in PSE146 and the locus gpsb014 was detected in PSE235. No private (rare) alleles were observed in exotic accessions and improved varieties from Burkina Faso (Table 2).

\section{Genetic diversity pattern}

The mean genetic diversity $(\mathrm{He})$ for all accessions was 0.45 and varied among populations and markers. For individual markers, it ranged from 0.05 (gpsb133) to 0.79 (Xtxp285). The genetic value was relatively large in three populations of Burkina (West Region=0.49, Eastern Region $=0.45$ and Southwest Region=0.44) compared to the exotic accessions (0.42). The observed heterozygosity $(\mathrm{Ho})$ ranged from $0.00 \quad$ (mSBCIR238, gpsb079, gpsb133, mSBCIR222, Sbag02, Xcup011, mSBCIR314 and Xtxp285) to 0.054 (Xtxp225). The mean $H o$ was 0.012 and was very low across local populations $(H o=0.01)$ from different regions. It was absolutely null in exotic accessions $(H o=0.00)$ (Figure 1).

\section{Genetic differentiation}

The overall genetic differentiation $(F s t=0.04)$ was low but significant and detected differences among populations at a probability of $\mathrm{P}<0.05$ (Table 4). The Fst mean value among accessions was estimated to be 0.26. The lowest genetic distance or differentiation was shown by $m S B C I R 225$ and $m S B C I R 222$ with a Fst value of 0.03 and the highest was Xtxp225 with a Fst value of 0.60. The pairwise population of $F s t$ values showed that there was no significant differentiation among populations of the three regions (West, Southwest and East) but detected low genetic 
distance between exotic accessions and local populations from the three regions. The Nei genetic identity indicated that accessions of the three regions are closely related to each other and are slightly different from exotic material (Table 3). The intra-population genetic differentiation (Fis) was very high (0.973) (Table 4). The mean Fis among accessions was 0.96 and varied from 0.71 (mSBCIR314) to 1 (mSBCIR238, gpsb014, gpsb79, gpsb133, mSBCIR188, mSBCIR222, Sbagb02, Xup011 and Sb5-236). The high value of $F i s=0.96$ indicates a weak level of cross pollination.

\section{Analysis of molecular variance}

The analysis of molecular variance assigns $4 \%$ of genetic variation to the differentiation among populations, $93 \%$ to differentiation among individuals and $3 \%$ to differences within individuals in a population. These variations were significant $(\mathrm{P}<0.05)$ (Table 4).

\section{Factorial Analysis of Genetic diversity}

Factorial analysis of 186 accessions was performed based on Rogers-Tanimoto dissimilarity index. The two first axes accounted for $34.23 \%$ of the total variation with $27.91 \%$ for axis 1 and $6.35 \%$ for axis 2 . Three major groups were identified. Groups 1 and 2 were mainly composed of traditional varieties or landraces from the three regions and group 3 includes exotic materials and local improved varieties from Burkina Faso. An exotic source of stay-green QTLs (B35) was distinct from the other accessions. Goups 1 and 2 contain most of the local guinea landraces whereas group 3 contains caudatum, bicolor and the intermediate race (caudatumguinea). The local landraces are very closely related and seem to have many alleles in common. Improved varieties are also closely related but, slightly different from local accessions. The durra line (B35) did not fit in any three groups but was closer to the improved varieties than the local accessions (Figure 2).

The $F_{s t}$ values among groups confirmed the factorial structure. The improved varieties and exotic accessions are different from local accessions. The Nei genetic identity also confirms the close relationship among local accessions and improved varieties. The high $F_{i s}$ (0.973) indicates significant gene flow among local accessions of the three regions.

\section{Classification using Neighbor-Joining analysis}

Genetic structure using "NeighborJoining" method displays three major clusters. Cluster 1 contains three sub-clusters. Cluster one is composed of exotic material and local improved varieties. Cluster 2 is mostly composed of local guinea accessions from the different regions. Cluster 3 contains only the exotic accession, B35, a durra line and source of stay-green QTLs (Figure 3).

\section{Marker Polymorphism assessment for stay- green trait}

The characterization of the polymorphism between stay-green donor (B35) and local improved varieties was done using 14 SSR markers linked to different QTLs. Only one marker (mSBCIR222) failed to reveal differences in alleles among B35 and local improved varieties. At the loci $m S B C I R 238$ and $m S B C I R 225$, only Sariaso02 and Sariaso07 show different allele positions from B35. At the loci Xtxp23 and Xtxp123, 2 local improved varieties (Sariaso02 and Sariaso14) have different alleles than B35. Three varieties (Sariaso02, Sariaso07 and Sariaso11) have different alleles at locus Xtxp72 and only one variety is different from B35 at the following loci (Xtxp015, Xtxp03, gpsb032, mSBCIR314, Xtxp055, Xtxp225). All the improved varieties show different alleles from with B35 at two loci (Xtxp285, Sb5-236) (Table5). 
Table 1: Descriptive parameters for genetic diversity.

\begin{tabular}{llllllll}
\hline Marker & Stg status & N & Fis & Fst & Ho & He & PIC \\
\hline$m S B C I R 238$ & Stg & 5.00 & 1.00 & 0.34 & 0.000 & 0.59 & 0.50 \\
gpsb014 & NStg & 5.00 & 1.00 & 0.24 & 0.005 & 0.60 & 0.55 \\
gpsb079 & NStg & 4.00 & 1.00 & 0.39 & 0.000 & 0.55 & 0.48 \\
gpsb098 & NStg & 5.00 & 0.99 & 0.18 & 0.011 & 0.59 & 0.53 \\
gpsb123 & NStg & 5.00 & 0.98 & 0.39 & 0.011 & 0.63 & 0.56 \\
gpsb133 & NStg & 2.00 & 1.00 & 0.33 & 0.000 & 0.05 & 0.05 \\
gpsb136 & NStg & 4.00 & 0.94 & 0.33 & 0.043 & 0.56 & 0.46 \\
gpsb158 & NStg & 3.00 & 0.99 & 0.46 & 0.005 & 0.26 & 0.24 \\
mSBCIR188 & NStg & 4.00 & 1.00 & 0.39 & 0.005 & 0.36 & 0.32 \\
mSBCIR222 & Stg & 3.00 & 1.00 & 0.03 & 0.000 & 0.14 & 0.14 \\
mSBCIR243 & NStg & 3.00 & 0.98 & 0.19 & 0.016 & 0.20 & 0.19 \\
Sbagb02 & NStg & 4.00 & 1.00 & 0.26 & 0.000 & 0.52 & 0.40 \\
Xcup011 & NStg & 3.00 & 1.00 & 0.24 & 0.000 & 0.34 & 0.29 \\
Xcup043 & NStg & 3.00 & 0.97 & 0.33 & 0.016 & 0.45 & 0.41 \\
Xtxp015 & Stg & 5.00 & 0.99 & 0.17 & 0.005 & 0.20 & 0.20 \\
Xtxp23 & Stg & 7.00 & 0.87 & 0.14 & 0.016 & 0.68 & 0.65 \\
gpsb032 & Stg & 3.00 & 0.89 & 0.06 & 0.027 & 0.61 & 0.52 \\
Xtxp003 & Stg & 3.00 & 0.97 & 0.28 & 0.005 & 0.56 & 0.47 \\
mSBCIR225 & Stg & 4.00 & 0.99 & 0.03 & 0.032 & 0.11 & 0.11 \\
mSBCIR314 & Stg & 3.00 & 0.71 & 0.23 & 0.000 & 0.54 & 0.44 \\
Sb5-236 & Stg & 5.00 & 1.00 & 0.09 & 0.011 & 0.42 & 0.39 \\
Xtxp055 & Stg & 4.00 & 0.98 & 0.10 & 0.022 & 0.58 & 0.51 \\
Xtxp072 & Stg & 3.00 & 0.98 & 0.33 & 0.005 & 0.56 & 0.46 \\
Xtxp123 & Stg & 5.00 & 0.99 & 0.31 & 0.016 & 0.57 & 0.53 \\
Xtxp225 & Stg & 3.00 & 0.87 & 0.60 & 0.054 & 0.23 & 0.22 \\
Xtxp285 & Stg & 6.00 & 0.82 & 0.33 & 0.000 & 0.79 & 0.76 \\
Mean & & 4.00 & 0.96 & 0.26 & 0.012 & 0.45 & 0.40 \\
\hline
\end{tabular}

$\mathrm{N}$ : alleles number; Fis: measure of heterozygosity deficit in a sub-population; Fst: measure of genetic differentiation among sub-populations Ho: Observed heterozygosity; He: Expected heterozygosity; PIC: Polymorphsim Information Conten

Table 2: List of Samples with One or More Private Alleles.

\begin{tabular}{clcc}
\hline Sample & Pop & No. Loci with Private Alleles & Loci with Private Alleles \\
\hline ER & PSE146 & 1 & Xtxp15 \\
WR & PSE206 & 1 & Xtx123 \\
WR & PSE226A & 1 & Xtx123 \\
WR & PSE234 & 1 & Xtxp285 \\
WR & PSE235 & 1 & gpsb014 \\
WR & PSE288 & 1 & Xtx123 \\
WR & PSE65 & 1 & Xtx123 \\
WR & PSE69 & 1 & Xtx123 \\
\hline PSE: "Prospection Sorgho Ecotype"
\end{tabular}


Table 3: Genetic differentiation among populations.

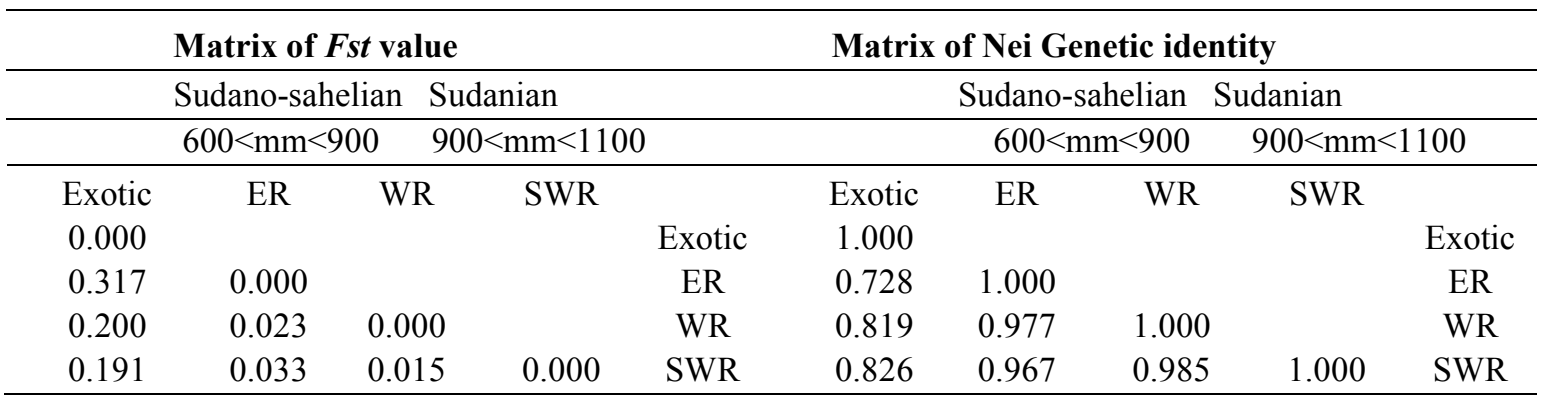

Exotic accessions (Accessions from Africa, America and Asia), ER: Eastern Region, WR: Western region and WSR: Southwest region.

Table 4: Result of molecular variance analysis with 186 accessions.

\begin{tabular}{lllllllll}
\hline Source & df & SS & MS & Est. Var. & P (\%) & Fis & Fst & Prob \\
\hline Among Pops & 5 & 114.55 & 22.9 & 0.24 & $4 \%$ & 0.973 & 0.04 & 0.01 \\
Among Indiv & 180 & 2037.08 & 11.31 & 5.58 & $93 \%$ & & & \\
Within Indiv & 186 & 28.5 & 0.153 & 0.153 & $3 \%$ & & & \\
Total & 371 & 2180.13 & & 5.97 & $100 \%$ & & & \\
\hline
\end{tabular}

df: degree of freedom; SS: Sum Square; MS: Mean Square; P: Polymorphism rate; Var: Variance; $\boldsymbol{F}_{i s}$ : heterozygosity deficit in a sub-population; $\boldsymbol{F}_{\text {st }}$ : genetic differentiation among sub-populations. $\mathrm{P}<0.05$

Table 5: Polymorphism assessment among source of stay-green (B35) and local improved varieties.

\begin{tabular}{|c|c|c|c|c|c|c|c|c|c|c|c|c|c|}
\hline Samples & Stg & Min & Max & LG & B35 & Sar02 & Sar03 & Sar04 & Sar06 & Sar07 & Sar08 & Sar11 & Sar14 \\
\hline$m S B C I R 238$ & Stg3 & 84 & 101 & 2 & $\mathrm{a}$ & $\mathrm{b}$ & $\mathrm{a}$ & $\mathrm{a}$ & $\mathrm{a}$ & $\mathrm{a}$ & $\mathrm{a}$ & $\mathrm{a}$ & $\mathrm{a}$ \\
\hline$m S B C I R 222$ & Stg 4 & 119 & 140 & 5 & $\mathrm{a}$ & $\mathrm{a}$ & $\mathrm{a}$ & $\mathrm{a}$ & $\mathrm{a}$ & $\mathrm{a}$ & $\mathrm{a}$ & $\mathrm{a}$ & $\mathrm{a}$ \\
\hline Xtxp15 & Stg 4 & 236 & 278 & 5 & $\mathrm{~b}$ & $\mathrm{a}$ & $\mathrm{c}$ & $\mathrm{a}$ & $\mathrm{a}$ & $\mathrm{a}$ & $\mathrm{a}$ & $\mathrm{b}$ & $\mathrm{a}$ \\
\hline Xtxp23 & Stg 4 & 174 & 221 & 5 & $b$ & $\mathrm{a}$ & $\mathrm{b}$ & $\mathrm{b}$ & $\mathrm{b}$ & b & $\mathrm{b}$ & b & $\mathrm{a}$ \\
\hline gpsb032 & Stg 4 & 278 & 324 & 5 & $b$ & $\mathrm{~b}$ & $\mathrm{c}$ & $\mathrm{a}$ & $\mathrm{c}$ & $\mathrm{a}$ & $\mathrm{c}$ & $\mathrm{c}$ & $\mathrm{c}$ \\
\hline Xtxp03 & StgB & 204 & 264 & 2 & $\mathrm{c}$ & $\mathrm{a}$ & $\mathrm{b}$ & $\mathrm{b}$ & $\mathrm{c}$ & $\mathrm{b}$ & $\mathrm{b}$ & $\mathrm{b}$ & $\mathrm{b}$ \\
\hline$m S B C I R 225$ & Stg2 & 142 & 160 & 3 & $\mathrm{a}$ & $\mathrm{a}$ & $\mathrm{a}$ & $\mathrm{a}$ & $\mathrm{a}$ & $\mathrm{b}$ & $\mathrm{a}$ & $\mathrm{a}$ & $\mathrm{a}$ \\
\hline$m S B C I R 314$ & Stg1\&2 & 211 & 236 & 3 & $\mathrm{~b}$ & b & $\mathrm{a}$ & $\mathrm{a}$ & $\mathrm{a}$ & $\mathrm{a}$ & $\mathrm{a}$ & $\mathrm{a}$ & $\mathrm{a}$ \\
\hline Sb5-236 & Stg2 & 180 & 200 & 3 & $\mathrm{c}$ & b & $\mathrm{a}$ & b & $\mathrm{b}$ & $\mathrm{b}$ & $\mathrm{b}$ & $\mathrm{b}$ & $\mathrm{b}$ \\
\hline Xtxp55 & StgB & 221 & 236 & 2 & $\mathrm{c}$ & $b$ & $\mathrm{a}$ & $\mathrm{c}$ & $\mathrm{b}$ & $\mathrm{b}$ & $\mathrm{b}$ & b & $\mathrm{b}$ \\
\hline Xtxp72 & StgB & 95 & 125 & 2 & $\mathrm{a}$ & $\mathrm{b}$ & $\mathrm{a}$ & $\mathrm{a}$ & $\mathrm{a}$ & $\mathrm{c}$ & $\mathrm{a}$ & $\mathrm{b}$ & $\mathrm{a}$ \\
\hline Xtxp123 & Stg 4 & 264 & 304 & 5 & $\mathrm{c}$ & $\mathrm{a}$ & $\mathrm{c}$ & $\mathrm{c}$ & $\mathrm{c}$ & $\mathrm{c}$ & $\mathrm{c}$ & $\mathrm{c}$ & $\mathrm{b}$ \\
\hline Xtxp225 & Stg 4 & 174 & 204 & 5 & $\mathrm{a}$ & $\mathrm{a}$ & b & b & b & $\mathrm{b}$ & $\mathrm{b}$ & $\mathrm{b}$ & $\mathrm{b}$ \\
\hline Xtxp285 & Stg1 & 240 & 278 & 3 & $\mathrm{c}$ & $\mathrm{a}$ & $\mathrm{b}$ & $\mathrm{b}$ & $\mathrm{b}$ & $\mathrm{b}$ & $\mathrm{b}$ & $\mathrm{b}$ & $\mathrm{b}$ \\
\hline
\end{tabular}




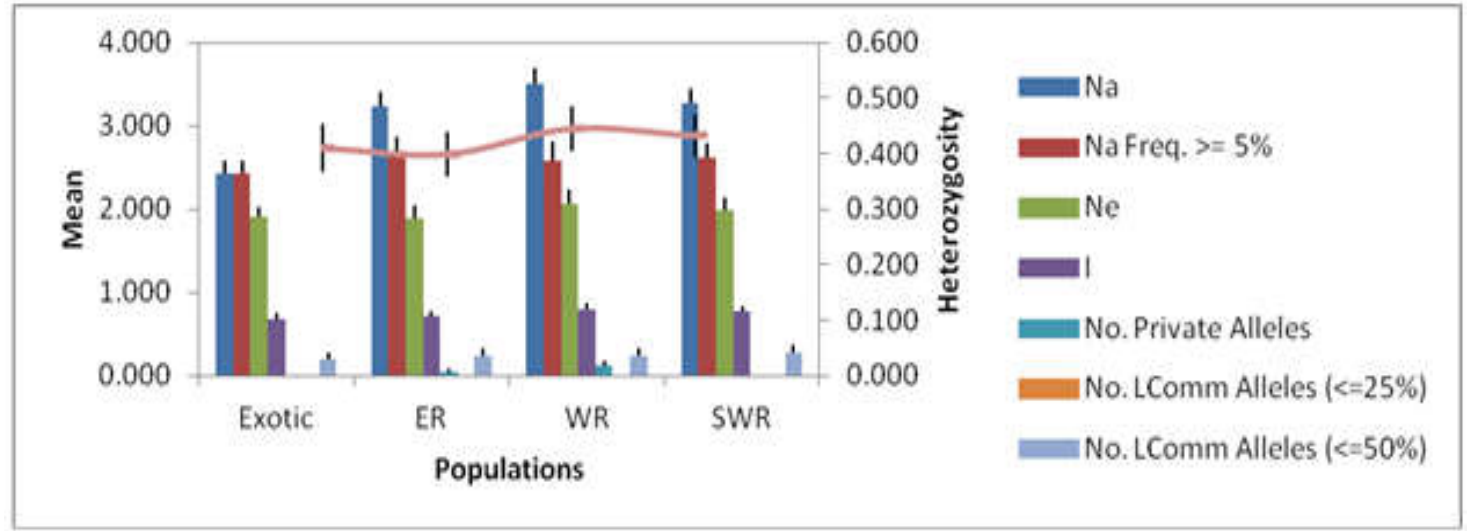

Figure 1: Illustration of the allelic patterns across populations.

Na: Number of different alleles; Na Freq: Frequency of different alleles; Ne: Number of effective alleles; I: Shanon Index; No.private alleles: Number of private alleles; No.Lcomm Alleles: Number of common alleles.

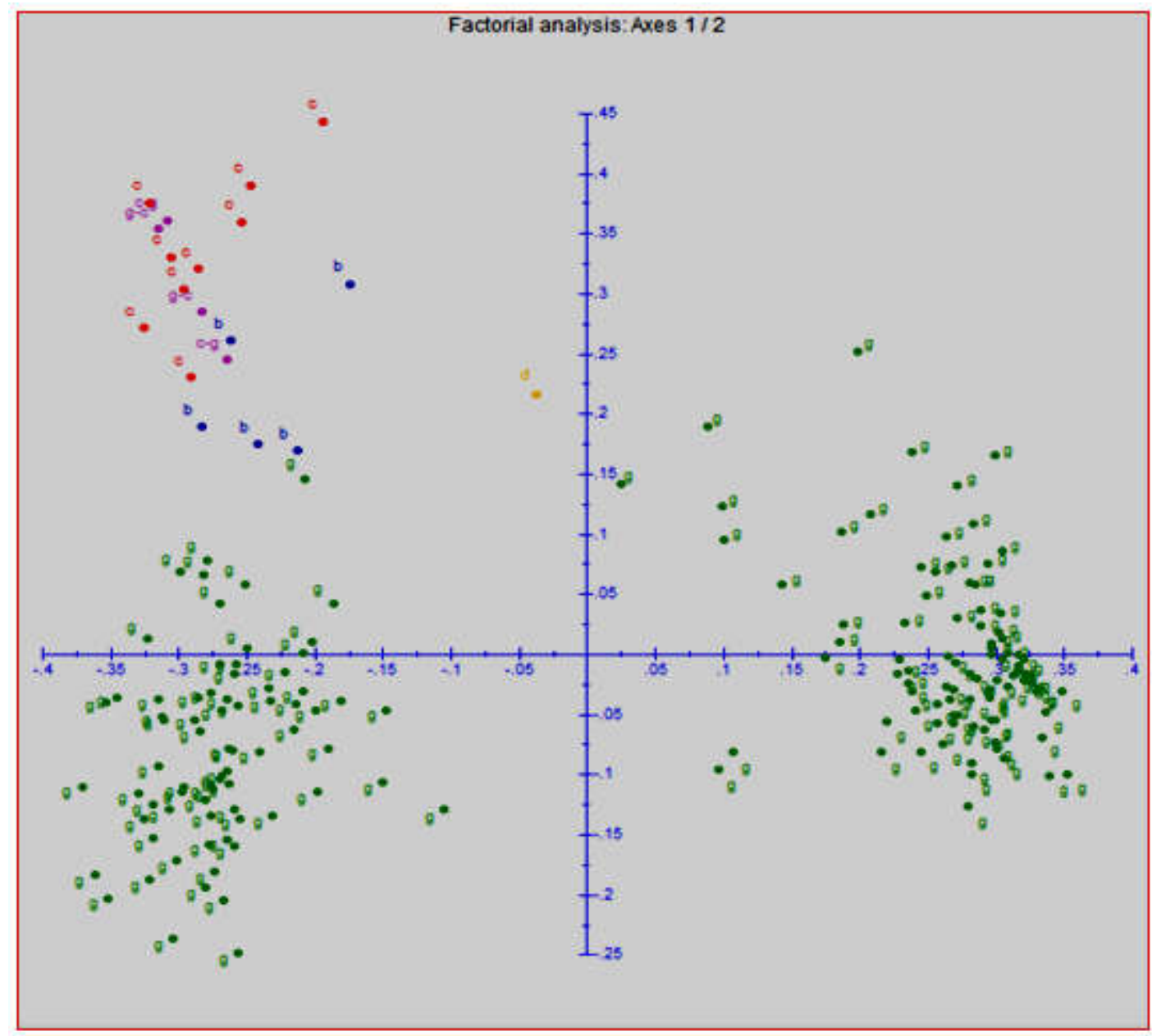

Figure 2: Factorial analysis illustrating the grouping of local sorghum accessions of three regions of Burkina Faso and some exotic material.

Legend: g:guinea c:caudatum; b:bicolor; d:durra; g-c:guinea-caudatum or c-g:caudtum-guinea 


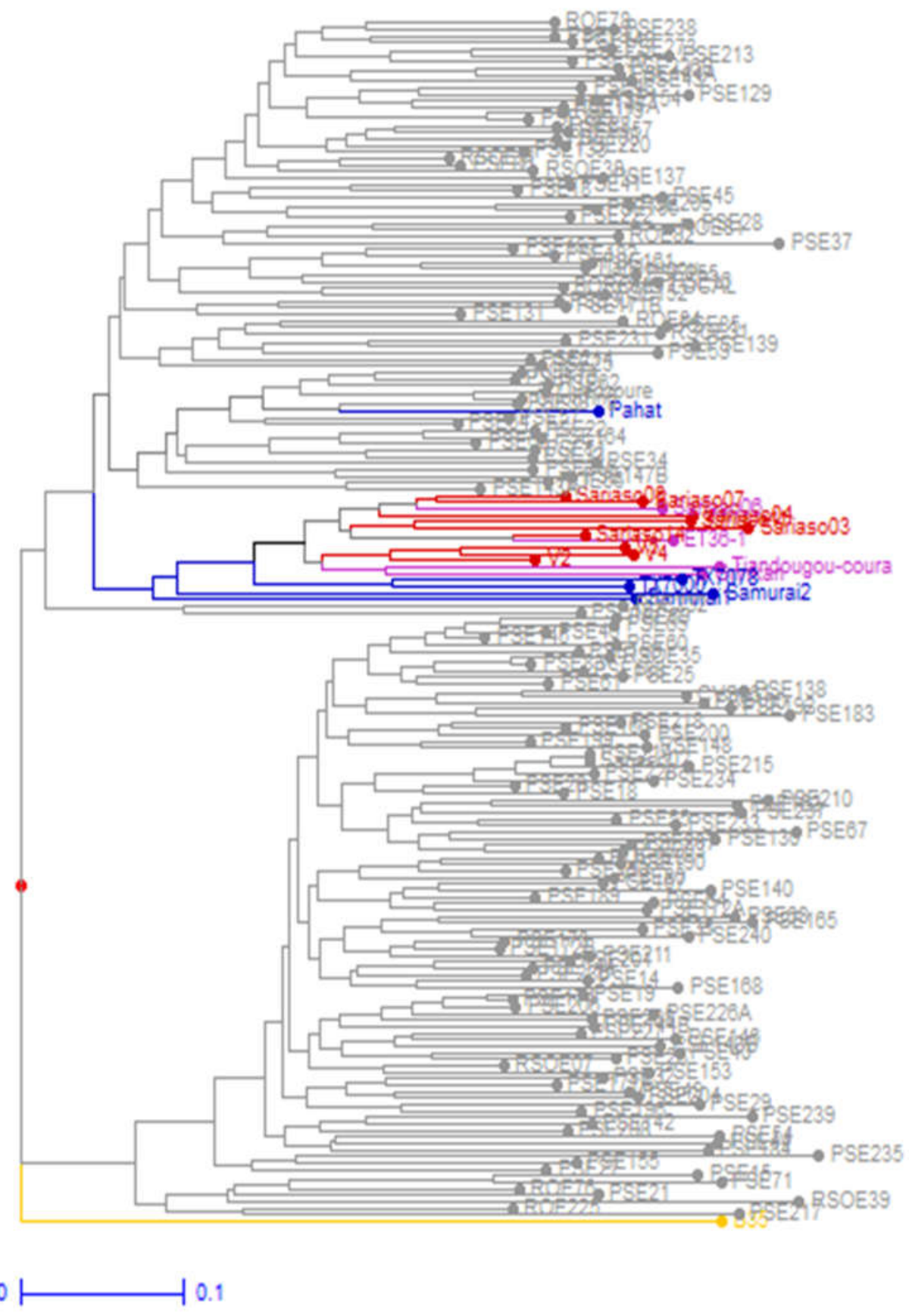

Figure 3: Dendrogram illustrating the genetic diversity with 26 SSRs markers within 186 accessions using "Neighbor Joining" method.

Legend: $\mathrm{O}$ :guinea $\mathrm{O}$ :caudatum; $\mathrm{O}$ :bicolor; $\mathrm{O}$ :durra; $\mathrm{O}^{\text {g-c:guinea-caudatum or c-g:caudtum-guinea }}$ 


\section{DISCUSSION}

The genetic diversity values $(2<\mathrm{N}<7$; $\mathrm{N}_{\mathrm{m}}=4 ; \mathrm{Nt}=108 ; \mathrm{He}=0.45$ and $\mathrm{PIC}=0.40$ ) found in this study differed from some previous studies. The medium value of PIC indicates the relevance of SSRs markers involved in the study to discriminate accessions. The diversity was higher than that $(H e=0.37)$ reported by Barro-Kodombo et al. (2008) on grain sorghum and slightly below the value $(0.47)$ reported by Nebie (2014) on sweet stem sorghum. The genetic diversity values $(0.674$ and 0.61 respectively) reported by Billot et al. (2013) and Sawaodgo (2015) were all beyond the values found in the present study. This weak diversity may be due to the relatively small number of accessions used here compared to the large number (3367) used by Billot et al. (2013). It may also be due to the number and type of microsatellite markers used in the present study. Overall, this result explained the slight genetic variation among accessions from the three different regions. The observed heterozygosity $(\mathrm{Ho})$ mean was 0.012 , indicating that most markers detected one allele per accession. This indicates that accessions contain few heterozygous individuals and are highly inbred and could be used as pure lines in a breeding programme. In fact, since the collection in 1999, the accessions have been regularly regenerated by enforced self-pollination. Billot et al. (2013) found similar result on a collections maintained by self-pollination. In contrast, high Ho value (0.11) was observed by Barnaud et al. (2007) when assessing samples obtained directly from landraces.

Local accessions contain an important number of private alleles whereas no private alleles were observed in improved varieties. These private alleles are present at loci (Xtxp15, Xtxp023, Xtxp123 and Xtxp285) which are linked to stay-green QTLs. This indicates probably the presence of stay-green alleles in the background of theses local guinea accessions. This important finding and may lead to investigation for stay-green QTL identification in future studies.

The Fst value was low but significant and differentiates among populations, especially between exotic material and local populations. Most of the collected accessions were guinea landraces while local improved varieties and exotic materials included bicolor race (TX7000, TX7078, Samurai1\&2 and Pahat), durra (B35) and some intermediates of guinea-caudatum (Grinkan, Sariaso06, Tiandougou-coura and ET36-1). Most of the improved varieties are of caudatum race (V2, V4, V5, S34, Sariaso03, Sariaso04, Sariaso07, Sariaso08, Sariaso11 and Sariaso14). The local guinea accessions, local improved varieties and exotic materials were differentiated according the racial origins. Barro-Kodombo et al. (2008) found weak genetic differentiation among traditional and introduced varieties due turn-over of introduced varieties among farmers.

Genetic differentiation between regions and climatic zones was very low $(0.015$ to 0.033). Populations from the West and Southwest were more closely related $(F s t=0.015)$ than populations from the East. The Eastern region is geographically distant from the two other regions but is located in the same ecological zone (Sudano-sahelian) with the Southwest region. Nebie (2014) reported also a weak genetic differentiation in different climatic zones of the country. However, his investigation revealed that the higher differentiation was exhibited by accession from distant climatic zones. The Nei genetic identity confirms the relatedness among local populations compared to exotic material. The close relationship among local populations could be due to the common historical origin of the guinea gene pool (Zongo, 1991; Barro-Kodombo et al., 2008). The similarity among populations from West and Southwest could be due to gene flow within accessions as the consequence of extensive exchange of materials between farmers from these regions. The analysis of 
molecular variance shows only $4 \%$ genetic variation was attributed to the differentiation among populations, and $3 \%$ to the variation within individuals. The most genetic variation (93\%) was due to differentiation among individuals.

Sorghum accessions from the three different regions and exotic material were separated into three main groups using 26 SSRs markers for genetic structure. A strong correlation exists between the factorial analysis and Neighbor-joining clusters in the grouping of the accessions. Most of the accessions in groups 1 and 2 from the factorial distribution matched, respectively, with the accessions in cluster 1 and 2 displayed by the Neighbor-joining analysis. The exotic materials and local improved varieties from group 3 of the factorial analysis were found in sub-cluster 2 of cluster 1 of the Neighborjoining analysis. The unique durra line, B35, was totally isolated from other accessions. The genetic structure found in this study appears to be more strongly linked to the race of the accessions than other factors. The presence of two guinea groups is due to the existence of two guinea sub-race (guinea gambicum and guinea margaritiferm) in Burkina. Nebie (2014) found similar results working on sweet stem sorghum collections from Burkina Faso. In contrast with our findings, Barro-Kodombo et al. (2008) found a genetic structure linked to the kernel colour. The separation of durra line (B35) from the other accessions is due to its particular characteristics and origin. This genotype possesses 6 QTLs for stay-green (Stg1, Stg2, Stg3, Stg4, StgA and StgB) linked to specific loci. Fourteen of these loci were used in this study. The separation of B35 from the local improved varieties and local accessions indicates that most of these genotypes do not possess the portions of chromosomes (QTLs) responsible for the stay-green trait.

The polymorphism assessment shows that two of the markers (Xtxp285 and Sb5236) linked to the stay-green QTLs in B35 differ from the local improved varieties. In contrast, all the local improved varieties were genetically similar to B35 at the locus $m S B C I R 222$. This indicates that the two loci (Xtxp285 and Sb5-236) could be used as markers for foreground selection of the corresponding stay-green QTLs (Stg3 and Stg2) into local varieties while $m S B C I R 222$ would not be useful for the incorporation of Stg4. The different allelic forms exhibited by these loci (Xtxp015, Xtxp03, gpsb032, $m S B C I R 314$, Xtxp055 and Xtxp225) between $\mathrm{B} 35$ and local varieties involve the existence of a genetic dissimilarity, indicating the lack of the target regions responsible for the staygreen trait in most of the varieties. The loci Xtxp015, gpsb032 and Xtxp225 could be used to incorporate Stg4 into the improved varieties except for Sariaso11 and Sariaso02. Xtxp03 could be used for the introgression of $\mathrm{StgB}$ into improved varieties except for Sariaso06. Xtxp055 and $m S B C I R 314$ could be used to incorporate the Stg1 and 2 and Stg4 into local varieties except for Sariaso02 and Sariaso04. The polymorphism at loci $m S B C I R 238$ and mSBCIR225 between B35, Sariaso02 and Sariaso07 could be used in the incorporation of QTLs of Stg3 and Stg2. Xtxp023 Xtxp123 and Xtxp072 would be useful to incorporate Stg4 and StgB. According to Langridge et al. (2001), useful markers in breeding should reveal polymorphism in different populations derived from a wide range of different parental genotypes.

\section{Conclusion}

Local sorghum accessions have relatively important genetic variability in Burkina Faso and genetic improvement is feasible using the variability found in the present work. The highly-inbred status of accessions should be used in breeding programmes for selection of traits of interest. The low differentiation among local accessions of distinct regions in the two agroecological zones is due to significant exchange of cropping material between farmers and suggests that diversity at the 
regional scale is not significantly different from diversity at the agro-ecological scale.

The differentiation of local accessions from exotic material shows that these accessions have not been submitted to a breeding process. The presence of private or specific alleles indicates the existence of unknown genes in the local germplasm. Some of these alleles are found in stay-green chromosomal regions and may play an important role in drought tolerance. Finally, the high polymorphism among local improved varieties and a source (B35) of stay-green suggests the use of these markers to introgress the trait into our local varieties through marker-assisted selection would be successful.

\section{COMPETING INTERESTS}

The authors declare that they have no competing interests.

\section{AUTHORS' CONTRIBUTIONS}

NO conducted the study, was responsible for data analysis and wrote the manuscript; JS and HT assisted in the conception of the study. PT and EYD contributed in the design of the study and participated in the data interpretation. VG contributed to improve the language (American English) of the manuscript. All authors have made their contribution in editing the manuscript and approved the final version.

\section{ACKNOWLEDGMENTS}

The authors would like to thank, Alliance for Green revolution in Africa (AGRA), through the West Africa Centre for Crop Improvement (WACCI) for the award of the grant to conduct the research, the CERAAS laboratory for the genotyping activity.

\section{REFERENCES}

Araus JL, Slafer GA, Reynolds MP, Royo C. 2002. Plant breeding and water relations in C3 cereals: what should we breed for? Ann. Bot-London, 89: 925-940.
Assogbadjo AE, Amadji G, Kakaï GR, Mama A, Sinsin B, Van Damme P. 2009. Evaluation écologique et ethnobotanique de Jatropha curcas L. au Bénin. Int. J. Biol. Chem. Sci., 3(5): 1065-1077.

Barnaud A, Deu M, Garine E, McKey D, Joly H. 2007. Local genetic diversity of sorghum in a village in northern Cameroon: structure and dynamics of landraces. Theoretical and Applied Genetics, 114: 237-248.

Barro-Kondombo PC, Vom-Brocke K, Chantereau J, Sagnard F, Zongo JD. 2008. Variabilité phénotypique des sorghos locaux de deux régions agricoles du Burkina Faso: la Boucle du Mouhoun et le Centre-Nord. Cahiers Agricultures, 17: 107-113.

Barro-Kondombo PC. 2010. Diversité agromorphologique et génétique de variétés locales de sorgho (Sorghum bicolor [L.] Moench) au Burkina Faso. Eléments pour la valorisation des ressources génétiques locales. Thèse de doctorat, Université de Ouagadougou, $112 \mathrm{p}$.

Billot C, Rivallan R, Sall MN, Fonceka D, Deu M, et al. 2012. A reference microsatellite kit to assess for genetic diversity of Sorghum bicolor (Poaceae). American Journal of Botany, 99: e245e250.

Billot C, Ramu P, Bouchet S, Chantereau J, Deu M, Gardes L, Noyer J-L, Rami JF, Rivallan R., Li Y, Lu P, Wang T, Folkertsma RT, Arnaud EC, Upadhyaya HD, Glaszmann JC and Hash T. 2013. Massives sorghum collection genotyped with markers to enhance use of global genetic resources. PLOS one, 8(4). Doi:10.1371/journal.pone.0059714.

Borrell AK, Hammer GL, Henzel RG. 2000.

Does maintaining green leafarea in sorghum improve yield under drought? II. Dry matter production and yield. Crop Science, 40:1037 1048.

Bhattramakki D, Dong J, Chhabra AK, Hart G. 2000. An integrated SSR and RFLP linkage map of Sorghum bicolor (L) Moench. Genome, 43: 988-1002. 
FAO. 2015. FAOSTAT. www.faostat.org consulted le 25/07/2016.

FAO. 2009. The state of food insecurity in world. 61p.

Frost R, Xi Y, He H. 2007. Modification of the surfaces of Wyoming montmorillonite by the cationic surfactants alkyl trimethyl, dialkyl dimethyl and trialkyl methyl ammonium bromides. Journal of Colloid and Interface Science, 305(1): 150-158.

Harlan JR. 1975. Les plantes cultivées et l'homme (Crops and man. trad. Franç., 1987). Collection techniques vivantes, PUF, $414 \mathrm{p}$.

Harris K, Subudi PK, Borrell A, Jordan D, Roseonw D, Nguyen H, klein R, Klein P, Mullet J. 2007. Sorghum stay-green QTL individually reduce post-flowering drought-induced leaf senescence. J. Exp. Bot., 58(2): 327-338.

Kassahun BB, Bidinger RF, Hash TC, Kuruvinashetti SM. 2009. Stay-green expression in early generation sorghum [Sorghum bicolor (L.) Moench] QTL introgression lines. Euphytica, 172: 351362.

Kebede H, Subudhi PK, Rosenow DT, Nguyen HT. 2001. Quantitative trait loci influencing drought tolerance in grain sorghum (Sorghum bicolor L. Moench). Theoretical and Applied Genetics, 103: 266-276.

Kong L, Dong J, Hart GE. 2000. Characteristics, linkage-map positions and allelic differentiation of [Sorghum bicolor (L) Moench] DNA simple sequence repeats (SSRs). Theoretical Applied Genetics, 101: 438-448.

Langridge P, Lagudah ES, Holton TA, Appels R, Sharp PJ, Chalmers KJ. 2001. Trends in genetic and genome analyses in wheat. Australian Journal of Agricultural Research, 52: 1043-1077.

Missihoun AA, Agbangla C, AdoukonouSagbadja H, Ahanhanzo C, Vodouhè R. 2012. Gestion traditionnelle et statut des ressources génétiques du sorgho (Sorghum bicolor L. Moench) au Nord-Ouest du Bénin. Int. J. Biol. Chem. Sci., 6(3): 10031018.

DOI:http://dx.doi.org/10.4314/ijbcs.v6i3.8

Nebié B. 2014. Diversité génétique des sorghos à tiges sucrée [Sorghum bicolor (L) Moench] du Burkina Faso. Thèse unique, Université de Ouagadougou, UFR/SVT, 118p.

Nebié B, Nanema KR, Kando/Bationo P, Traore RE, Labeyrie V, Sawadogo N, Sawadogo M, Zongo DJ. 2013. Variation de caractères agromorphologiques et du Brix d'une collection de sorghos à tige sucrée du Burkina Faso. Int. J. Biol. Chem. Sci., 7(5): 1919-1928. DOI : http://dx.doi.org/10.4314/ijbcs.v7i5.12.

Payton SP, Cartor R, Kayla MC, Pathsn MS, Rosenow DT, Nguyen HT. 2003. Transcriptional profiling of drought response in sorghum, Abs: 76, Poster: Functional Genomics. American Society of Plant Biologists Annual Meeting, August 8, 2002, Texas.

Perrier X, Jacquemoud-Collet JP. 2006. DARwin software. http://darwin.cirad.fr/darwin

Rockall, Smouse PE, 2006. Genalex version 41.6Xla.

Rosenow DT, Clark LE. 1991. Drought tolerance in sorghum. In proc $36^{\text {th }}$ Annual Cornand Sorghum res conf, December 911, 1981, Chicago, Illinois, 1995: 17-30.

Sagnard F, Deu M, Dembélé D, Leblois R, Touré L, Diakité M, Calatayud C, Vaksmann M, Bouchet S, Mallé Y, Togola S, Traoré PCS. 2011. Genetic diversity, structure, gene flow and evolutionary relationships within the Sorghum bicolor wild-weedy-crop complex in a western African region. Theorical and Applied Genetics, 16 p.

Sawadogo N, Nebie B, Kiebre Mariam, Kando BP, Nanema KR, Traore ER, Naoura G, Sawadogo M, Zongo DJ. 2014. Caractérisation agromorphologique des sorghos à grains sucrés (Sorghumbicolor 
(L.) Moench) du Burkina Faso, Int. J. Biol. Chem. Sci., 8(5): 2183-2197. DOI: http://dx.doi.org/10.4314/ijbcs.v8i5.22

Sawadogo N. 2015. Diversité génétique des sorghos à grains sucrés [Sorghum bicolor (L) Moench] du Burkina Faso. Thèse Unique, Université de Ouagadougou, UFR/SVT, 185p.

Schloss SJ, Mitchell SE, White GM, Kukatla R, Bowers JE, Paterson AH, Kresovich S. 2002. Characterization of RFLP probe sequences for gene discovery and SSR development in Sorghum bicolor (L.) Moench. Theoretical and Applied Genetics, 105: 912-920.

Subudhi PK, Rosenow DT, Nguyen HT. 2003. Quantitative trait loci for the stay green trait in sorghum (Sorghum bicolor L. Moench): consistency across genetic backgrounds and environments.
Theoretical and Applied Genetics, 101: 733-741.

Zongo JD. 1991. Ressources génétiques des sorghos (Sorghum bicolor L. Moench) du Burkina Faso: Evaluation agromorphologique et génétique. Thèse de doctorat, Université d'Abidjan, 175 p.

Zongo JD, Gouyon PH, Sarr A, Sandmeier M. 2005. Genetic diversity and phylogenic relations among Sahelian sorghum accessions. Genetic Resources and Crop Evolution, 52: 869 - 878.

Zougmoré R. 2003. Integrated water and nutrient management for sorghum production in semi-arid Burkina. Tropical resources management papers no 45, Wageningen University and Research Center, Wageningen, the Netherlands 2003, 205 pp. 